\title{
POLİTİK KÜRESELLEŞME VE SÜRDÜRÜLEBİLİR KALKINMA
}

\author{
Taner GÜNEY1 \\ İclal ÇÖĞURCÜ2
}

Atıf/ ( : Güney, T. ve Çöğürcü, İ. (2019). Politik küreselleşme ve sürdürülebilir kalkınma. Hitit Üniversitesi Sosyal Bilimler Enstitüsü Dergisi, 12(2), 341-354. doi: 10.17218/hititsosbil.542493

Özet: Bu çalışmanın amacı gelişmiş ve gelişmekte olan ülkelerde politik küreselleşmenin sürdürülebilir kalkınma üzerindeki etkisini analiz etmektir. Bu amaçla 36 gelişmiş ve 84 gelişmekte olan ülkenin 1990-2015 dönemine ait verileri kullanılmıştır. Sistem-GMM yöntemleriyle elde edilen tahmin sonuçlarına göre, hem gelişmiş hem de gelişmekte olan ülkelerde politik küreselleşme sürdürülebilir kalkınma üzerinde pozitif yönlü ve istatistiksel olarak anlamlı bir etkiye sahiptir. Politik küreselleşmenin sürdürülebilir kalkınma üzerindeki pozitif yönlü etkisi, gelişmekte olan ülkelere göre gelişmiş ülkelerde daha yüksektir. Politik küreselleşmenin alt dallarılan de facto politik küreselleşme ve de jure politik küreselleşmenin sürdürülebilir kalkınma üzerindeki etkisi de analizedilmiştir. Tüm ülkelerde ve gelişmiş ülkelerde de facto ve de jure politik küreselleşme sürdürülebilirkalkınmayı pozitif yönlü etkilemektedir. Bu ülkelerde, de jure politik küreselleşme sürdürülebilirkalkınmaüzerinde daha büyük bir etkiye sahiptir. Gelişmekte olan ülkelerde ise de jure politik küreselleşme sürdürülebilir kalkınma üzerinde pozitif yönlü etkiye sahipken, de facto politik küreselleşme sürdürülebilir kalkınmayı negatif yönlü etkilemektedir.

Anahtar Kelimeler: Politik Küreselleşme, Sürdürülebilir Kalkınma, Gelişmiş Ülkeler, Gelişmekte Olan Ülkeler, Sistem-GMM

\section{Political Globalization And Sustainable Development}

Citation/ (O: Güney, T. ve Çöğürcü, İ. (2019). Political globalization and sustainable development. Hitit University Journal of Social Sciences Institute, 12(2), 341-354. doi: 10.17218/hititsosbi1.542493

Abstract: The aim of this study is to analyze the impact of political globalization on sustainable development in developed and developing countries. For this purpose, the data of 36 developed and 84 developing countries, covering the period of 1990-2015, were used. According to the results of the system-GMM methods, political globalization has a positive effect on sustainable development in both developed and developing countries. The positive effect of political globalization on sustainable developmentis higher in developed countries than in developing countries. The impact of de facto political globalization and de jure political globalization on sustainable development has also been analyzed. In all countries and developed countries, de facto and de jure political globalization has apositive impact on sustainable development. In these countries, de jure political globalization has agreater impact on sustainable development. In developing countries, while jure political globalization has a positive effect on sustainable development, de facto political globalization negatively affects sustainable development.

Keywords: Political Globalization, Sustainable Development, Developed Countries, Developing Countries, System-GMM

Makale Geliş Tarihi: 20.3.2019 Makale Kabul Tarihi: 14.12.2019

1 Sorumlu Yazar, Doç. Dr., Karamanoğlu Mehmetbey Üniversitesi, İktisadi ve İdari Bilimler Fakültesi, İktisat Bölümü, tanerguney@kmu.edu.tr, http://orcid.org/0000-0002-7201-2057.

2 Dr. Öğr. Üyesi, Karamanoğlu Mehmetbey Üniversitesi, İktisadi ve İdari Bilimler Fakültesi, İktisat Bölümü, icogurcu@kmu.edu.tr 


\section{GİRIŞ}

Dünyanın son yirmi yıllındaki değişiminde oldukça etkili olan küreselleşme, akademi ve politika çevrelerinde önemli miktarda tartışmaya maruz kalmıştır. Her ne kadar küreselleşmenin gerçekleşmekte olup olmadığı veya dünyanın son yıllardaki değişimini açıklamanın iyi bir yolu olup olmadığı konusunda tartışılsa da, baskın olan fikir birliği, küreselleşmenin gerçek olduğuve zamanımızın doğasını karakterize ettiği hakkındadır (Held ve diğerleri, 1999, s.14; Karagül, 2001, s.203). Bu anlamda küreselleşme ticaret, sermaye akımları, yenilikçi fırsatlar ve kültürel bağlar gibi önemli değişkenleri etkileyerek ülkelerin ekonomilerini birbirine bağlamayan çok güçlü bir kavramdır. Bununla birlikte küreselleşen dünyada ülkelerin finansal ve ticari açıklık düzeyi yükselmekte, ülkelerin sahip olduğu ekonomik karaktere bağlı olarak, ülkelerin ekonomik büyüme ve kalkınmaları da, bu yükselmeden olumlu yönde etkilenmektedir (Yay ve Aksoy, 2018). Ancak küreselleşmenin çevreye zararlı etkileri de bulunmaktadır. Küreselleşen dünyanın çevre kirliliği ve karbon emisyonu daha fazla olmakta, bu kirlilik ve karbon salınımı, ekolojinin bozulmasına ve küresel iklimin değişmesine neden olabilmektedir (Ki-Hoon ve Min, 2014; Shahbaz ve diğerleri, 2015; Shahbaz ve diğerleri, 2017; Shahbaz ve diğerleri, 2018). Bu nedenle küreselleşme sürdürülebilir kalkınma ile yakından ilişkilidir. Brundtland Raporu olarak da bilinen ve Dünya Çevre ve Kalkınma Komisyonu (WCED, 1987) tarafından yayınlanan Ortak Geleceğimiz (Our Common Future) raporunda, sürdürülebilir kalkınma, gelecek kuşakları kendi ihtiyaçlarını karşılamadan mahrum etmemek için, toplumun verimli kaynak kullanımı seviyeleri yoluyla bugünün gereksinimlerini karşılamak olarak tanımlanmaktadır. Dolayısıyla küreselleşen dünyanın neden olduğu karbon emisyonu ve çevre kirliliği, sürdürülebilir kalkınma düzeyinin de azalmasına neden olabilmektedir. Bu çalışmanın amacı ise gelişmiş ve gelişmekte olan ülkelerde politik küreselleşmenin sürdürülebilir kalkınma üzerindeki etkisini analiz etmektir. Çalışmada 120 ülkenin 1990-2015 dönemine ait verilerine yer verilmiştir. Bu ülkelerden 36's1 gelişmiş, 84'ü gelişmekte olan ülke özelliğini taşımaktadır. Sistem-GMM yöntemiyle yürütülen analizler, politik küreselleşmenin sürdürülebilir kalkınma üzerinde, gelişmiş ve gelişmekte olan ülkelerde, pozitif yönlü ve istatistiks el olarak anlamlı bir etkiye sahip olduğunu göstermiştir.

Çalışmanın giriş bölümünden sonraki bölümler şöyle organize edilmiştir. Çalışmanın ikinci bölümünde ilgili literatür, üçüncü bölümünde politik küreselleşme ve sürdürülebilir kalkınma ilişkisi, dördüncü bölümünde veriler ve tahmin yöntemi açıklanmaktadır. Beşinci bölümde politik küreselleşme ve sürdürülebilir kalkınma ilişkisine dair tahmin sonuçlarına yer verilmektedir. Altıncı ve son bölümde ise sonuç kısmı yer almaktadır.

\section{LİTERATÜR}

Globalleşmenin ekonomik değişkenler üzerindeki etkisine dair oldukça geniş bir literatür oluşmuştur ${ }^{3}$. Örneğin, ticaret ${ }^{4}$, sermaye akımlar1 ${ }^{5}$, finansal açıklık $k^{6}$ gibi değişkenler bu geniş literatür içinde yer almaktadır. Diğer yandan globalleşme ile ekonomik büyüme iliş kisi literatürde oldukça yoğun biçimde araştırma konusu yapılan iki değişken durumundadır (Potrafke, 2015) ${ }^{7}$. Bunlardan biri olan Chang ve Lee (2011), 10 eski komünist ülke ile 18 OECD ülkesinde, ekonomik globalleşmenin ekonomik büyümeyi pozitif olarak etkilediğini göstermiştir. Capello ve Perucca (2015)'a göre, Avrupa Birliği'nin küresel olarak açık olan bölgelerinde yer alan ülkeler, diğer bölgelerinde yer alan ülkelerden daha iyi ekonomik performans göstermektedir. Stiftung (2014), Böhmer ve diğerleri (2016) ve Weiß ve diğerleri (2018), gelişmiş ve gelişmekte olan toplam 42

\footnotetext{
3 İlgili literatür için Potrafke (2015) ve Lee ve diğerleri (2015) gibi çalışmalara bakılabilir.

4 İlgili literatür için Felbermayr ve Gröschl (2013)'e bakılabilir.

5 İlgili literatür için Alfaro ve diğerleri (2006)'ya bakılabilir.

6 İlgili literatür için Rodrik ve Subramanian (2009'a bakılabilir.

${ }^{7}$ Potrafke (2015) bu alanda da oldukça genis bir literatür sunmaktadır.
} 
ülkede, ekonomik küreselleşmenin büyüme üzerinde pozitif yönlü etkide bulunduğunu belirtmektedir. Bununla birlikte, globalleşmenin her ülkede büyümeyi etkileyemeyeceğini savunan çalışmalar da bulunmaktadır. Örneğin Birdsall (2002) ve Samimi ve Jenatabadi (2014)'e göre ekonomik globalleşme özellikle gelişmemiş özellikte olan ülkelerde, büyümeyi azaltabilmektedir. Diğer yandan küreselleşme ve sürdürülebilir kalkınma ilişkisi daha dar kapsama sahiptir. Küreselleşme ve sürdürülebilir kalkınma ilişkisi için, literatürde Rondinelli (2007), Ashford ve diğerleri (2011), Mahtaney (2013), Köhler (2014) ve Parnell (2018) gibi teorik özellikte olan çalışmalar bulunduğu gibi, çok az sayıda da olsa, ampirik nitelikteki çalışmalar da yer almaktadır. Bu alandaki az sayıda ampirik çalışmalardan biri olan Güney (2018), ekonomik küreselleşmenin sürdürülebilir kalkınma üzerindeki etkisini analiz etmiştir. 124 geliş mekte olan ülkenin 1990-2015 dönemine ait verilerini kullanarak, Sistem-GMM yöntemiyle elde edilen tahmin sonuçlarına göre ekonomik globalleşme sürdürülebilir kalkınmayı pozitif yönlü etkilemektedir. Bir diğer çalışmada Güney (2018), gelişmekte olan ülkelerde finansal küreselleşmenin sürdürülebilir kalkınma üzerindeki etkisini incelemiştir. Analiz sonuçları buiki değişken arasında bir eşbütünleşme ilişkisi olduğunu ortaya koymaktadır. FMOLS ve DOLS tahminlerine göre, ülkelerin finansal küreselleşme düzeyi arttığında sürdürülebilir kalkınma düzeyi de uzun vadede artmaktadır. Ülkelerin finansal küreselleşme düzeyi \%1 arttığında, FMOLS sonuçlarına göre sürdürülebilir kalkınma düzeyi en az \%0.05, ile DOLS sonuçlarına göre ise en az \%0.04 oranında artış göstermektedir. Bu çalış mada ise, gelişmiş ve gelişmekte olan ülkelerde, politik küreselleşmenin sürdürülebilir kalkınma üzerindeki etkisi analiz edilmektedir. Buyönüyle bu çalışma, literatürde, bu alandaki eksikliğe katkı yapar nitelikte olan bir çalışma durumundadir.

\section{POLİTIKK KÜRESELLEŞME VE SÜRDÜRÜLEBİLİR KALKINMA}

Üzerinde çok fazla tartışılan küreselleşme, başta devletler olmak üzere ekonomik ilişkiler, sosyal ve siyasal ağlar ve toplumların etki ettiği yerel, ulusal ve bölgesel süreçleri içeren bir süreklilik olarak tanımlanabilir (Held ve diğerleri, 1999). Bir süreklilik olarak tanımlanan küreselleşmeyi anlamak için iklim değişikliği veya çevresel kirlilik gibi hususları göz önünde bulundurmak faydalı olabilir. Çünkü çölleşme, çevresel bozulma, kaynakların tükenmesi, dünya ticareti, küresel iletişim, medya, nüfus hareketleri, mülteci krizleri, suçlar, savaşlar ve güvenlik sorunları gibi önemli faktörler, artık çok nadiren kendi bölgelerinde sınırlı kalmaktadır (Homer-Dixon, 1999; Barnett, 2001). Diğer bir deyişle dünyanın herhangi bir bölgesindeki olayların, kararların ve faaliyetlerin diğer bölgelerdeki bireyler ve topluluklar için önemi vardır ve bu sosyal, ekonomikve politik faaliyetler dünya çapına yayılmaktadır. Örneğin Hindistan ve Çin gibi ülkelerdeki ekonomik büyüme, sınai gelişme ve tüketim sadece bu ülkelerin ekonomisi ve ekolojisini etkilememektedir. Bu ülkelerin ekonomik faaliyetleri daha geniş bir ekolojik ve ekonomik çevreye ulaşarak, dünyayı etkileyen küresel bir etkiye dönüşmektedir. Dolayısıyla dünyadaki kaynakların tükenmesi, su kıtlığı ve iklim değişikliği gibi kilit konular, küreselleşmenin çevresel bozulmaya olan etkilerindendir. Diğer yandan sürdürülebilir kalkınma, toplumlar arasındaki politik ve çevresel etkileşimin yanı sıra, ekolojik ve çevresel sorunların karmaşıklığıyla birleşerek geniş bir yelpaze halinde gelişen bir kavramdır (Blewitt, 2012). Sürdürülebilir kalkınmanın doğasında, gezegenin doğal çevresini korumak bulunmaktadır. Bu amaca ulaşmak için sürdürülebilir kalkınma, hem ülke içinde hem de ülkeler arasında sosyal ve ekonomik eşitliği teşvik etmektedir. Bu nedenle, sürdürülebilir kalkınma, bir yakınsama süreci olarak kavramlaş tırılabilir. Dünyamızı daha iyi bir yer yapmak için tasarlanan her türlü ciddi düşünce, eylem veya herhangi bir ölçeklendirme önemli bir unsur haline gelmektedir. Sürdürülebilir kalkınmanın ölçeklendirilmesi açısından çok iyi bir çalışma olan Grainger (2004), bu amaçla ekolojik, sosyal ve politik 
unsurlardan oluşan bir tablo oluşturmuştur (s.55). Tablo 1'e göre ekolojik ölçekteki her değişkenin mutlaka sosyo-politik ölçekte bir karşılığı vardır.

Tablo 1. Ekolojik ve Sosyo-Politik Ölçekler

\begin{tabular}{ll}
\hline Ekolojik Ölçek & Sosyo-Politik Ölçek \\
\hline Biyosfer & Dünya \\
Biyom tipi & Uluslararası bölgeler \\
Biyom & Devlet \\
Peyzaj & Bölge \\
Ekosistem & Bölge 1: şehir, kasaba \\
Toplum & Bölge 2: köy,toplum, komşuluk \\
Nüfus Organizması & Hanehalkı \\
\hline
\end{tabular}

Kaynak: Grainger (2004, s.55)

Örneğin dünya, ekolojik ölçekteki canlıların yaşam alanının toplamı olan biyosfere yani yerküreye denk gelmektedir. Uluslararası bölgesel tanımlamalar aynı iklim koşullarının yaşandığı, aynı bitki örtüsüne sahip olan geniş coğrafi alanları gösteren biyomun eşitidir. Sonuç olarak sosyo-politik ölçekteki her karar ve faaliyet mutlaka ekolojik ölçekteki dengini etkilemektedir. Politik kararların sürdürülebilir kalkınma üzerindeki etkisine iyi bir örnek Birleşmiş Milletler (UN)'in düzenlediği toplantılardır. Örneğin UN, 1992'de Birlessmiş Milletler Çevre ve Kalkınma Konferansı (UNCED)'i düzenlemiştir. UNCED sonuç raporu olan United Nations Sustainable Development (1992)'ye göre, politik liderlerin temsil etiği devletlerin tamamı yaşanabilir bir gelecek için güçlerini birleştirerek küresel bir ortaklık inşa etmeyi amaçlamaktadır. Buna göre asıl amacı dünyada yaşayan insanoğlunun bugün ve yarın hayatta kalmasını güvence altına almak olmak raporda, insan hayatının ekolojik, sosyal ve ekonomik ilerlemenin dengesi üzerine kurulu olduğu vurgulanmıştır. Bu nedenle bu toplantı ortak geleceğimiz için dünya çapında yapılan politik bir katılım programıdır. Bu programların en sonuncusu 2015 yılında Paris'te yapılmıştır. Paris'te toplanan 195 ülke sera gazlarını azaltmayı, kömür, petrol ve doğalgazdan uzaklaşmayı öngören anlaşmayı benimseyerek iklim değişikliği sorununu çözecek bir uzlaşmaya (UN, 2015) imza atmıştır. Politik liderlerin temsil ettiği ülkeler, küresel 1sınma artışını "2 derecenin çok altında" tutmakla yükümlü hale gelmiştir. Bu yükümlülük gereği, yükselen denizler ve aşırı ısınan hava koşullarıyla mücadele etmek için gelişmiş ülkeler, gelişmekte olan ülkelere milyarlarca dolar vermeyi taahhüt etmiştir. Gelişmekte olan ülkeler ise enerji alt yapılarını yenilenebilir enerji kullanımına daha uygun hale getirmeyi hedeflemiştir. Sonuç olarak sürdürülebilir kalkınmaya dair kararların verilmesi, hedeflerinin belirlenmesi ve bu hedeflere ulaşılmasını sağlayacak politika ve düzenlemelerin hayata geçirilmesi, tamamıla politik kararların bir arada ve uzlaş mayla uygulanmasına bağlıdır.

\section{VERİ VE YÖNTEM}

(1) nolu model, bu çalışmanın amacı olan politik küreselleşmenin sürdürülebilir kalkınma üzerindeki etkisini tahmin etmek için kullanılmaktadır:

$\operatorname{Sd}_{\text {it }}=\beta_{1} \mathrm{Sd}_{\mathrm{it}-1}+\beta_{2} \mathrm{Küresel}_{\text {it }}+\varepsilon_{\text {it }}$

(1) nolu eşitlikte $\mathrm{Sd}_{\text {it }}$ sürdürülebilir kalkınmayı, Sdit-1 i ülkesinde t-1 dönemine ait sürdürülebilir kalkınmayı, Küresel ülkelerin politik küreselleşme düzeyini göstermektedir. Politik küreselleşme

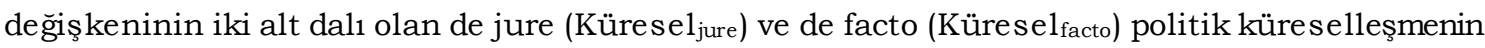
de Sd üzerindeki etkisi analiz edilmiştir. Küreseljure bir ülkenin üyesi olduğu uluslararası kuruluşların sayısı, iki veya daha fazla ülke arasında imzalanan ve 1945 'ten bu yana her ülkenin 
en yüksek yasama organı tarafından onaylanan uluslararası anlaşmaların sayısı ve ikili yatırım anlaşmaları olan bir ülkenin belirgin anlaşma ortaklarının sayısı olmak üzere üç farklı göstergenin ortalamasıdır. Küreselfacto değişkeni de üç göstergeden oluşmaktadır. Bunlar; bir ülkedeki elçilik sayısı, kişi başına Birleşmiş Milletler Güvenlik Konseyi Görevlerine katkıda bulunan personel sayısı ve ülkenin üyesi olduğu uluslararası odaklı sivil toplum örgütlerinin (STK) sayısıdır. İlgili değişkenlere ait 1990-2015 dönemini kapsayan veriler KOF Swiss Economic Institute (KOF)'dan alınmıştır. KOF verileri 0 ile 100 arasında değişmektedir ve bu verilerin doğal logaritması alınarak analizlerde kullanılmıştır.

Aidt (2010) Güney (2017) ve Güney (2019) çalışmalarında sürdürülebilir kalkınma değişkenin göstergesi olarak düzeltilmiş net tasarruf (Ans) kullanmıştır. Bu nedenle bu çalışmada da sürdürülebilir kalkınma göstergesi olarak Ans tercih edilmiştir. Ans hesaplamasında ulusal brüt tasarruftan, sermayenin aşınma payı (amortisman) çıkarılarak ulusal net tasarruf elde edilir. Ulusal net tasarrufa, eğitim harcamaları eklenirken, kullanılan doğal sermayeden elde edilen ranttaki azalma ve karbondioksit emisyonu zararı çıkarılır. Böylelikle düzeltilmiş net sarruf eldedilir. Ans verileri Dünya Bankası'ndan (WB) ${ }^{8}$ alınmıştır. Ans verileri negatif ve çok yüksek değerler aldığı için aşağıdaki (2) nolu formülle standart verilere dönüştürülmüştür. Bu formülle değişkenin verileri, 0 ile 1 arasında değişmektedir.

Standard Ans $=\frac{\text { Yıl Değeri-En Küçük Değer }}{\text { En Büyük Değer-En Küçük Değer }}$

Bu çalışmada (1) nolu eşitliğin tahmini için bir dinamik panel veri model olan Sistem-GMM yöntemi tercih edilmiştir. Dinamik modellerde değişkenlerin birinci farkı alındığında, bazı değişkenlere ait verilerin bir kısmı veya tamamı kaybolabilmektedir. Dinamik modelde birincifark alma yerine ortogonal sapmalar yöntemini kullanan Arellano ve Bover (1995), bu sayede değişkenlere ait verilerin kısmen veya tamamen kaybolmasına engel olmaktadır. Diğer yandan dinamik modellerde modele bağımsız değişken olarak eklenen değişkenin gecikmeli değeri, aynı modele açıklayıcı değişkenlerden biri olarak eklenmektedir. Ancak bu durumda bağımlı değişkenin gecikmeli değeri ile kalıntılar korelasyonlu hale gelmektedir. Bu değişkenlerin korelasyonlu olması nedeniyle elde edilen tahminler tutarsiz olabilmektedir. Tahmin tutarsızlığının ortadan kaldırılabilmesi için bağımlı değişkenin gecikmeli değerini, açıklayıcı değişken olarak modele eklemek yerine, araç değişkenlerin kullanılması önerilmiştir (Tatoğlu, 2012). Blundell ve Bond (1998) tarafından önerilen tahmin yöntemi, yukarıda sayılan tahmin problemlerinin aşılabilmesi için, Anderson ve Hsiao (1981), Arellano ve Bond (1991) ve Arellano ve Bover (1995) tarafından önerilen yöntemlerden daha iyi olduğu is patlanmıştır (Baltagi, 2005). Bu çalışmada bu nedenle Blundell ve Bond (1998) tarafından önerilen tahmin yöntemi tercih edilmiştir. Sistem-GMM tahmininde kullanılacak araç değişkenler elde edilirken, araç değişken elde etme yöntemi nedeniyle, hata teriminlerinde birinci dereceden otokorelasyonun ortaya çıması gerekmektedir. Buna 1. dereceden otokorelasyon denmekte AR(1) testi ile sinanmaktadır. AR(1) istatistiksel olarak anlamlı olmalıdır. Modelde doğru araç değişkenlerin kullanılması ile 1. dereceden otokorelasyon ortadan kalkmaktadır. Bunun tespiti için 2. dereceden otokorelasyon tespitinde AR(2) kullanılmaktadır ve anlamsız olmalıdır. Ayrıca kullanılan araç değişkenlerin geçerli olup olmadığını tespit etmek için Sargan testi kullanılmaktadır. Sargan testi "araç değişkenler geçerlidir" boş hipotezini test ettiği için istatistiksel olarak anlamsız olmalıdır (Roodman, 2006). Modelin bir bütün halinde anlamlı olup olmadığını tes pit etmek için Wald testi

8 WB, Ans'yi Hamilton and Clemens (1999) ve Hamilton (2005)'in çalışmalarından yararlanarak hesaplamaktadır. 
kullanılmıştır. Çalışmada kullanılan değişkenlere ait tanımlayıcı istatistikler Tablo 2'de verilmiştir.

Tablo 2. Değişkenlerin Tanımlayıcı İs tatistikleri

\begin{tabular}{|c|c|c|c|c|c|c|}
\hline & & $\begin{array}{r}\text { Aritmetik } \\
\text { Ortalama }\end{array}$ & Maksimum & Minimum & $\begin{array}{r}\text { Standart } \\
\text { Hata }\end{array}$ & $\begin{array}{r}\text { Gözlem } \\
\text { Say1s1 }\end{array}$ \\
\hline \multirow{4}{*}{ Tüm Ülkeler } & $\overline{\mathrm{Sd}}$ & 0,0258 & 1,000 & 0,0000 & 0,049 & 2583 \\
\hline & Küresel & 4,1501 & 4,6006 & 2,3748 & 0,3445 & 3120 \\
\hline & Küresel $l_{\text {facto }}$ & 4,0591 & 4,5994 & 1,9866 & 0,4500 & 3120 \\
\hline & Küreseljure & 4,2110 & 4,6051 & 0,5693 & 0,3434 & 3120 \\
\hline \multirow{4}{*}{$\begin{array}{l}\text { Gelişmekte } \\
\text { Olan Ülkeler }\end{array}$} & $\mathrm{Sd}$ & 0,0191 & 1,000 & 0,0003 & 0,049 & 1771 \\
\hline & Küresel & 0,4264 & 4,5571 & 2,3748 & 0,3445 & 2184 \\
\hline & Küresel $1_{\text {facto }}$ & 0,4586 & 4,5680 & 1,9866 & 0,4500 & 2184 \\
\hline & Küresel $1_{\text {jure }}$ & 0,3922 & 4,5740 & 0,5693 & 0,3434 & 2184 \\
\hline \multirow{4}{*}{$\begin{array}{l}\text { Gelişmiş } \\
\text { Ülkeler }\end{array}$} & $\mathrm{Sd}$ & 0,0405 & 0,4830 & 0,0000 & 0,0523 & 812 \\
\hline & Küresel & 4,3532 & 4,6006 & 3,1757 & 0,2708 & 936 \\
\hline & Küresel $l_{\text {facto }}$ & 4,3061 & 4,5994 & 2,8330 & 0,3545 & 936 \\
\hline & Küresel jure & 4,3840 & 4,6051 & 2,8406 & 0,2531 & 936 \\
\hline
\end{tabular}

\section{TAHMİN SONUÇLARI}

Tablo 3, Tablo 4 ve Tablo 5 ilgili ülkelerin Sistem-GMM tahmin sonuçlarını göstermektedir. Tablo 3, gelişmiş ve gelişmekte olan 120 ülke için elde edilen tahminleri gösterirken, Tablo 4'te gelişmiş ülkeler, Tablo 5 'te ise gelişmekte olan ülkelere ait tahminler yer almaktadır. Tablolarda 1. sütunda

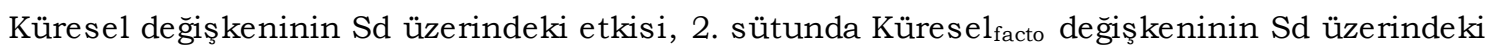
etkisi, son olarak 3. sütunda ise Küresel $1_{\text {jure }}$ değişkeninin Sd üzerindeki etkisi yer almaktadır.

Tablolardaki tahminlere göre, tüm sütunlarda, Wald testi modelin bir bütün halinde doğru olarak kurulduğunu göstermektedir. Sargan testinin tahminleri "araç değişkenleri” nin içsel değil, dışsal olduğunu göstermektedir. Dolayısıyla, geçerli araç değişkenler kullanılmıştır. 1. ve 2. seviye otokorelasyon olup olmadığı, $\operatorname{AR}(1)$ ve $A R(2)$ testleri ile sınanmıştır. AR(1) tahminine göre, üç tablodaki tahminlerin hepsinde 1 . derecede otokorelasyon varken, 2. derece otokorelasyon yoktur. Ayrıca tablolardaki tahminlere göre, tüm sütunlarda, Sd değişkeninin gecikmeli değeri olan $\mathrm{Sd}_{\text {it- }}$ 1, Sd üzerinde pozitif yönlü bir etkiye sahiptir. Tablo 3'e göre analizlere dahil edilen tüm ülkelerde, politik küreselleşme sürdürülebilir kalkınma üzerinde pozitif yönlü bir etkiye sahiptir. Pozitif yönlü bu etki, \%1 anlamlılık derecesinin bile altında, is tatistiksel olarak anlamlılı ğa sahiptir. Bu nedenle, ülkelerin politik küreselleşme düzeyi arttıkça, sürdürülebilir kalkınma düzeyi de artmaktadir.

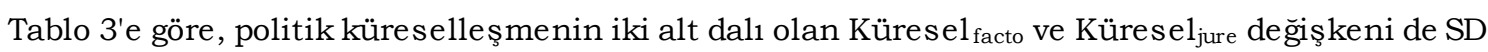
üzerinde pozitif yönlü etkiye sahiptir. Politik küreselleşmeye benzer biçimde, pozitif yönlü bu etkiler, \%1 anlamlılık derecesinin bile altında, is tatis tiksel olarak anlamlılı̆ga sahiptir. Dolayısıyla tüm ülkelerin, ülkedeki elçilik sayısı, kişi başına Birleşmiş Milletler Güvenlik Konseyi Görevlerine katkıda bulunan personel sayısı ve ülkenin üyesi olduğu uluslararası odaklı sivil toplum

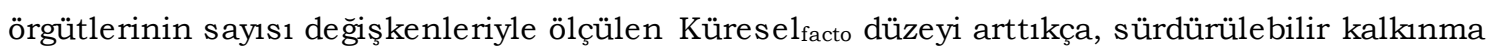
seviyesi artmaktadır. 
Tablo 3. Tüm Ülkeler İçin Sistem-GMM Tahminleri

\begin{tabular}{|c|c|c|c|}
\hline $\begin{array}{l}\text { Bağıms1z } \\
\text { Değiş kenler }\end{array}$ & 1 & 2 & 3 \\
\hline $\mathrm{Sd}_{\mathrm{it}-1}$ & $\begin{array}{r}1,066981^{*} \\
0,000013\end{array}$ & $\begin{array}{r}1,069291^{*} \\
0,000007\end{array}$ & $\begin{array}{r}1,071122^{*} \\
0,000006\end{array}$ \\
\hline Küresel & $\begin{array}{r}0,024644^{*} \\
0,000093\end{array}$ & & \\
\hline Küresel $l_{\text {facto }}$ & & $\begin{array}{r}0,011868^{*} \\
0,000040 \\
\end{array}$ & \\
\hline Küresel $1_{\text {jure }}$ & & & $\begin{array}{r}0,023519^{*} \\
0,000055\end{array}$ \\
\hline Sabit & $\begin{array}{r}0,277892^{*} \\
0,000457\end{array}$ & $\begin{array}{r}0,011207^{*} \\
0,000481\end{array}$ & $\begin{array}{r}0,400828^{*} \\
0,000363\end{array}$ \\
\hline Wald & $\begin{array}{r}5,93 e+10^{*} \\
(0,0000)\end{array}$ & $\begin{array}{r}1,42 \mathrm{e}+11^{*} \\
(0,0000)\end{array}$ & $\begin{array}{r}3,54 \mathrm{e}+10^{*} \\
(0,0000)\end{array}$ \\
\hline $\operatorname{AR}(1)$ & $\begin{array}{l}-2,8002 \\
(0,0051)\end{array}$ & $\begin{array}{l}-2,8116 \\
(0,0049)\end{array}$ & $\begin{array}{l}-2,7924 \\
(0,0052)\end{array}$ \\
\hline $\operatorname{AR}(2)$ & $\begin{array}{l}-1,5253 \\
(0,1272)\end{array}$ & $\begin{array}{l}-1,5263 \\
(0,1269)\end{array}$ & $\begin{array}{l}-1,4939 \\
(0,1352)\end{array}$ \\
\hline Sargan $\chi^{2}$ & 116,698 & 115,3708 & 116,2299 \\
\hline Gözlem & 2454 & 2454 & 2454 \\
\hline
\end{tabular}

Aynı şekilde, ülkenin üyesi olduğu uluslararası kuruluşların sayısı, iki veya daha fazla ülke arasında imzalanan ve 1945 'ten bu yana her ülkenin en yüksek yasama organı tarafından onaylanan uluslararası anlaşmaların sayısı ve ikili yatırım anlaşmaları olan bir ülkenin belirgin anlaşma ortaklarının sayısı değişkenleriyle ölçülen Küreseljure düzeyi de arttıkça, sürdürülebilir kalkınma seviyesi artmaktadır. Diğer yandan Küresel $1_{\text {jure }}$ değişkeninin sürdürülebilir kalkınma üzerindeki etkisi Küres $\mathrm{l}_{\text {facto }}$ değiş keninden yaklaşık iki kat daha yüks ektir. Dolayısıla analizlere dahil edilen tüm ülkeler açısından, politik küreselleşmenin Küresel jure alt dalının öğeleri olan faktörlerin geliştirilmesi için yapılacak düzenleme ve uygulamaların hayata geçirilmesi, sürdürülebilir kalkınmanın yüks eltilmesine çok katkı sağlayacaktır.

Tablo 4'te gelişmiş ülkeler için elde edilen Sistem-GMM tahminlerine göre, politik küreselleşme, sürdürülebilir kalkınma üzerinde pozitif yönlü ve istatistiksel olarak anlamlı bir etkiye sahiptir. Pozitif yönlü bu etki, \%1 anlamlılık derecesinin bile altında, istatistiksel olarak anlamlılığa sahiptir. Tüm ülkeler için elde edilen tahminlere benzer biçimde, politik küreselleşmenin iki alt dalı olan Küresel $l_{\text {facto }}$ ve Küresel $l_{\text {jure }}$ değişkeni de sürdürülebilir kalkınmayı pozitif olarak etkilemektedir. Pozitif yönlü bu etkiler, \%1 anlamlılık derecesinin bile altında, istatistikselolarak anlamlılığa sahiptir. Yine tüm ülkeler için elde edilen tahminlere benzer biçimde Küresel ${ }_{\text {jure }}$

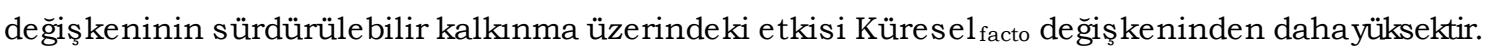
Dolayısıyla analizlere dahil edilen geliş miş ülkeler açısından, sürdürülebilir kalkınma düzeyinin daha da yükseltilmesi için, Küresel $l_{\text {jure }}$ değişkenini oluşturan faktörlerin geliştirilmesine öncelik verilmesi gerekmektedir. Tablo 4'te gelişmekte olan 84 ülke için elde edilen Sistem-GMM tahminlerini göstermektedir. Tabloya göre, politik küreselleşme değişkeni olan Küresel, sürdürülebilir kalkınma üzerinde pozitif yönlü ve istatistiksel olarak anlamlı bir etkiye sahiptir. Pozitif yönlü bu etki, \%1 anlamlılık derecesinin bile altında, istatistiksel olarak anlamlılığa sahiptir. 
Tablo 4. Gelişmiş Ülkeler İçin Sistem-GMM Tahminleri

\begin{tabular}{|c|c|c|c|}
\hline $\begin{array}{l}\text { Bağımsız } \\
\text { Değişkenler }\end{array}$ & 1 & 2 & 3 \\
\hline $\mathrm{Sd}_{\mathrm{it}-1}$ & $\begin{array}{r}0,941004^{*} \\
0,001062\end{array}$ & $\begin{array}{r}0,969618^{*} \\
0,000666\end{array}$ & $\begin{array}{r}0,978196^{*} \\
0,000593\end{array}$ \\
\hline Küresel & $\begin{array}{r}0,054398^{*} \\
0,003974\end{array}$ & & \\
\hline Küresel $1_{\text {facto }}$ & & $\begin{array}{r}0,037892^{*} \\
0,001609\end{array}$ & \\
\hline Küresel $l_{\text {jure }}$ & & & $\begin{array}{r}0,045674^{*} \\
0,001391\end{array}$ \\
\hline Sabit & $\begin{array}{r}-0,319759^{*} \\
0,029645\end{array}$ & $\begin{array}{r}-0,162097^{*} \\
0,007405\end{array}$ & $\begin{array}{r}-0,200239^{*} \\
0,006219\end{array}$ \\
\hline Wald & $\begin{array}{r}890630,23^{*} \\
(0,0000) \\
\end{array}$ & $\begin{array}{r}4,29 \mathrm{e}+06^{*} \\
(0,0000)\end{array}$ & $\begin{array}{r}3,88 \mathrm{e}+06^{*} \\
(0,0000)\end{array}$ \\
\hline $\operatorname{AR}(1)$ & $\begin{array}{l}-2,1085 \\
(0,0350)\end{array}$ & $\begin{array}{l}-2,1393 \\
(0,0324)\end{array}$ & $\begin{array}{l}-2,0846 \\
(0,0371)\end{array}$ \\
\hline $\operatorname{AR}(2)$ & $\begin{array}{r}-1,5732 \\
(0,1157)\end{array}$ & $\begin{array}{r}-0,6569 \\
(0,5112)\end{array}$ & $\begin{array}{l}-0,4351 \\
(0,6635)\end{array}$ \\
\hline Sargan $\chi^{2}$ & 33,577 & 33,9337 & 33,3217 \\
\hline Gözlem & 771 & 771 & 771 \\
\hline
\end{tabular}

Not: : ${ }^{*} \mathrm{p}<0.001$. Standart hata tahminleri italik verilmiştir. $\mathrm{p}$ - tahminleri parantez içinde yer almaktadır.

Bununla birlikte, Küresel'in Sd üzerindeki etkisi, gelişmiş ülkelere göre, gelişmekte olanülkelerde çok daha düşüktür. Politik küreselleşmenin iki alt dalı olan Küresel facto ve Küresel $1_{\text {jure }}$ değişkenlerinin SD üzerindeki etkisi gelişmekte ülkeler için farklı etkilere sahiptir. Küresel facto SD üzerindeki etkisi negatif yönlüdür. Üstelik negatif yönlü bu etki, \%1 anlamlılık derecesinin bile altında, is tatis tiksel olarak anlamlılığa sahiptir.

Tablo 5. Gelişmekte Olan Ülkeler İçin Sistem-GMM Tahminleri

\begin{tabular}{lrrr}
\hline Bağımsiz & 1 & 2 & 3 \\
Değişkenler & $1,066667^{*}$ & $1,208182^{*}$ \\
\hline Sdit-1 & 0,000043 & 0,000012 \\
\hline Küresel & $0,001782^{*}$ & 0,000049 & \\
& 0,000026 & & $0,003544^{*}$ \\
Küres el $l_{\text {facto }}$ & & $-0,000815^{*}$ & 0,000045 \\
\hline \multirow{2}{*}{ Küres el $l_{\text {jure }}$} & & 0,000044 & $-0,003544^{*}$ \\
& & & 0,000024 \\
\hline \multirow{2}{*}{ Sabit } & & $-0,047452^{*}$ & $(0,0000)$ \\
\hline \multirow{2}{*}{ Wald } & $0,004382^{*}$ & 0,002255 & $-1,9605$ \\
& 0,001262 & $7,58 \mathrm{e}+10^{*}$ & $(0,0499)$ \\
\hline \multirow{2}{*}{ AR(1) } & $9,98 \mathrm{e}+09^{*}$ & $(0,0000)$ & $-0,9424$ \\
\multirow{2}{*}{ AR(2) } & $(0,0000)$ & $-1,9555$ & $(0,3460)$ \\
\hline Sargan $\chi^{2}$ & $-1,9562$ & $(0,0497)$ & 79,7349 \\
\hline Gözlem & $(0,0499)$ & $-0,8703$ & 1508 \\
\hline
\end{tabular}

Not: : * $\mathrm{p}<0.001$. Standart hata tahminleri italik verilmiştir. $\mathrm{p}$ - tahminleri parantez içinde yer almaktadır.

$\mathrm{Bu}$ nedenle gelişmekte olan ülkelerde, ülkedeki elçilik sayısı, kişi başına Birleşmiş Milletler Güvenlik Konseyi Görevlerine katkıda bulunan personel sayısı ve ülkenin üyesi olduğu uluslararası odaklı sivil toplum örgütlerinin sayısı değişkenleriyle ölçülen Küreselfacto düzeyi 
arttıkça, sürdürülebilir kalkınma seviyesi azalmaktadır. Gelişmiş ülkelerin bu değişkenlerin azaltılmasını sağlayacak düzenlemeleri hayata geçirmesi, sürdürülebilir kalkınmanın arttırılmasına katkı yapacaktır. Bununla birlikte tüm ülkeler ve gelişmiş ülkelerde olduğu gibi, Küresel $l_{\text {jure }}$ değişkeninin SD üzerindeki etkisi pozitif yönlüdür. Pozitif yönlü bu etkiler, \%1 anlamlılık derecesinin bile altında, is tatis tiksel olarak anlamlılığa sahiptir. Dolayısıylagelişmekte olan ülkelerde sürdürülebilir kalkınma düzeyinin daha da yükseltilmesi için, bu değişkeni oluşturan faktörlerin geliştirilmesine öncelik verilmesinde fayda vardır. Diğer bir deyişle ülkenin üyesi olduğu uluslararası kuruluşların sayısı, iki veya daha fazla ülke arasında imzalanan ve 1945 'ten bu yana her ülkenin en yüksek yasama organı tarafından onaylanan uluslararas1 anlaşmaların sayısı ve ikili yatırım anlaşmaları olan bir ülkenin belirgin anlaşma ortaklarının sayısı arttıkça, gelişmekte olan ülkelerde sürdürülebilir kalkınma düzeyi de yükselecektir.

\section{SONUÇ}

Bu çalışmanın amacı 36 gelişmiş, 84 gelişmekte olan ülkede politik küreselleşmenin sürdürülebilir kalkınma üzerindeki etkisini analiz etmektir. Bu amaçla ülkelerin 1990-2015 dönemine ait verileriyle, Sistem-GMM yöntemi kullanılarak tahminler elde edilmiştir. Tahminler, politik küreselleşmenin düzeltilmiş net tasarrufla ölçülen sürdürülebilir kalkınma düzeyini pozitif yönlü etkilediğini göstermiştir. Pozitif yönlü bu etki gelişmiş ülkelerde, gelişmekte olan ülkelere

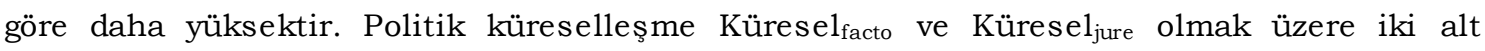
değişkenden oluşmaktadır. Bu alt dallardan ilki ülkedeki elçilik sayısı, kişi başına Birleşmiş Milletler Güvenlik Kons eyi Görevlerine katkıda bulunan personel sayısı ve ülkenin üyesi olduğu uluslararası odaklı sivil toplum örgütlerinin sayısı olmak üzere üç farklı göstergenin bileşimidir. İkinci alt dalın göstergeleri ise ülkenin üyesi olduğu uluslararası kuruluşların sayısı, iki veya daha fazla ülke arasında imzalanan ve 1945 ten bu yana her ülkenin en yüksek yasama organı tarafından onaylanan uluslararası anlaşmaların sayısı ve ikili yatırım anlaşmaları olan bir ülkenin belirgin anlaşma ortaklarının sayısıdır. Çalışmada bu iki alt dalın sürdürülebilir kalkınma üzerindeki etkisi de analiz edilmiştir. Analiz sonuçları gelişmiş ve gelişmekte olan ülkelerde, politik küreselleşmenin ikinci alt dalı olan Küresel jure'ün, sürdürülebilir kalkınma düzeyini arttırdığını göstermektedir. Dolayısıyla tüm ülkelerin, ülkenin üyesi olduğu uluslararası kuruluşların sayısı, iki veya daha fazla ülke arasında imzalanan ve 1945'ten bu yana her ülkenin en yüksek yasama organı tarafından onaylanan uluslararası anlaşmaların sayısı ve ikili yatırım anlaşmaları olan bir ülkenin belirgin anlaşma ortaklarının sayısı gibi faktörlerin geliştirilmesini sağlayacak yasal düzenleme ve politikaları hayata geçirmesi, sürdürülebilir kalkınma düzeyinin daha da yükselmesinde önemli rol oynayacaktır. Diğer yandan Küresel $1_{\text {facto, gelişmekte olan }}$ ülkelerde sürdürülebilir kalkınma üzerinde ne gatif etkiye sahiptir. Bu nedenle, gelişmekte olan ülkelerin bu alt dalı oluşturan göstergelerin azalmasına yardım edecek uygulama ve yasal düzenlemeleri hayata geçirmesi, kalkınmanın sürdürülebilirliği açısından önemli görülmektedir.

\section{KAYNAKÇA}

Aidt, T. S. (2010). Corruption and sustainable development (Rapor No.1061). Cambridge: Cambridge Working Papers in Economics.

Alfaro, L., Chanda, A., Kalemli-Ozcan, S. ve Sayek, S. (2006). How does foreign direct investment promote economic growth? Exploring the effects of financial markets on linkages (Rapor No. w12522). New York: National Bureau of Economic Research.

Anderson, T. W. ve Hsiao, C. (1981). Estimation of dynamic models with error component, . Journal of the American Statistical Association, 76(375), 598-606. 
Arellano, M. ve Bond, S. (1991). Some tests of specification for panel data: Monte Carlo evidence and an application to employment equations. Review of Economic Studies, 58(2), 277-297.

Arellano, M. ve Bover, O. (1995). Another look at the instrumental variable estimation of errorcomponents models. Journal of Econometrics, 68(1), 29-51.

Ashford, N. A. ve Hall, R. P. (2011). Technology, globalization, and sustainable development: Transforming the industrial state. New Haven: Yale University Press.

Baltagi, Badi H. (2005). Econometric analysis of panel data. New Jersey: John Wiley \& Sons.

Barnett, C. (2001). Culture, geography, and the arts of government. Environment and Planning D: Society and Space, 19(1), 7-24.

Birdsall, N. (2002). A stormy day on an open field: asymmetry and convergence in the global economy. Gruen, D., O’Brien, T., Lawson, J., (Ed.) Globalisation, living standards and inequality (s.66-87) içinde. Sydney: Reserve Bank of Australia and Australian.

Blewitt, J. (2012). Understanding sustainable development. London: Routledge.

Blundell, R. ve Bond, S. (1998). Initial conditions and moment restrictions in dynamic panel data models. Journal of Econometrics, 87(1), 115-143.

Böhmer, M., Weisser, J., Hoch, M. ve Schneidenbach, T. (2014). Globalization report 2014. Who benefits most from globalization?. Gütersloh: Bertelsmann Stiftung.

Capello, R. ve Perucca, G. (2015). Openness to globalization and regional growth patterns in CEE countries: from the EU accession to the economic crisis. JCMS: Journal of Common Market Studies, 53(2), 218-236.

Chang, C. P. ve Lee, C. C. (2011). The partisan comparisons for global effect on economic growth: Panel data analysis of former communist countries and European OECD members. Eastern European Economics, 49(6), 5-27.

United Nations Sustainable Development (1992). United Nations Conference on Environment \& Development. 3-14 Haziran 1992. Rio de Janerio, Brazil.

Felbermayr, G. ve Gröschl, J. (2013). Natural disasters and the effect of trade on income: A new panel IV approach. European Economic Review, 58, 18-30.

Grainger, A. (2004). The role of spatial scale and spatial interactions in sustainable development. Matin Purvis ve Alan Grainger (Ed.), Exploring Sustainable Development: Geographical Perspectives (s.35-50) içinde. London: Earthscan.

Güney T. (2017). Governance and sustainable development: how effective is governance?. The Journal of International Trade \& Economic Development, 26(3), 316-335.

Güney, T. (2018). Finansal küreselleşmenin kalkınma üzerindeki etkisi. Mine Nur Bozdoğan ve Atabek Movlyanova (Ed.), Farabi 3. Uluslararas1 Sosyal Bilimler Kongresi Tam Metin Kitab1 (s.210-2014) içinde. Ankara: İksad Yayınevi.

Güney, T. (2018). Ekonomik globalleşme ve sürdürülebilir kalkınma. Kürşat Özdaşl1, Murat Cem Demir, Olcay Tire, İbrahim Sena Arvas, Uğur Köksal Odabaş, İsmail Elagöz (Ed.), Sosyal, Beşeri ve İdari Bilimler Alanında Yenilikçi Yaklaşımlar Cilt 2 (s. 443-452) içinde. Ankara: Gece Kitaplığı. 
Güney, T. (2019). Renewable energy, non-renewable energy and sustainable development. International Journal of Sustainable Development \& World Ecology. doi: 10.1080/13504509.2019.1595214

Hamilton, K. ve Clemens, M. (1999). Genuine savings rates in developing countries. The World Bank Economic Review, 13(2), 333-356.

Hamilton, K. (2000). Sustaining economic welfare: Estimating changes in per capita wealth (Rapor No. 2498). New York: World Bank Policy Research Working Paper.

Held, D., McGrew, A., Goldblatt, D. ve Perraton, J. (2000). Global transformations: politics, economics and culture. London: Palgrave Macmillan.

Homer-Dixon, T. (1999). Environment, scarcity, and violence. Princeton: Princeton University Press.

Karagül, M. (2001). Küreselleşme küresel kriz ve Türkiye. Afyon Kocatepe Üniversitesi İ.I.B.F. Dergisi, 2(2), 203-217.

Ki-Hoon, L. ve Byung, M. (2014). Globalization and carbon constrained global economy: a fad or a trend?. Journal of Asia-Pacific Business, 15(2), 105-121.

Köhler, J. (2014). Globalization and sustainable development: Case study on international transport and sustainable development. The Journal of Environment \& Development, 23(1), 66-100.

Lee, C. C., Lee, C. C. ve Chang, C. P. (2015). Globalization, economic growth and institutional development in China. Global Economic Review, 44(1), 31-63.

Mahtaney, P. (2013). Globalization and sustainable economic development: Issues, insights, and inference. Berlin: Springer.

Parnell, S. (2018). Globalization and sustainable development: at the urban crossroad. The European Journal of Development Research, 30(2), 169-171.

Rodrik, D. ve Subramanian, A. (2009). Why did financial globalization disappoint?. IMF staff papers, 56(1), 112-138.

Potrafke, N. (2015). The evidence on globalisation. The World Economy, 38(3), 509-552.

Roodman, D. (2006). How to do xtabond2: an introduction to "difference" and "system" GMM in Stata (Rapor No. 103). Washington: The Center for Global Development Working Paper Series.

Rondinelli, D. A. (2007). Globalization of sustainable development: Principles and practices in transnational corporations. Multinational Business Review, 15(1), 1-24.

Samimi, P. ve Jenatabadi, H. S. (2014). Globalization and economic growth: Empirical evidence on the role of complementarities. PloS one, 9(4), e87824.

Shahbaz, M., Mallick, H., Mahalik, M. K. ve Loganathan, N. (2015). Does globalization impede environmental quality in India?. Ecological Indicators, 52, 379-393.

Shahbaz, M., Khan, S., Ali, A. ve Bhattacharya, M. (2017). The impact of globalization on CO2 emissions in China. The Singapore Economic Review, 62(04), 929-957. 
Shahbaz, M., Shahzad, S. J. H., Mahalik, M. K. ve Hammoudeh, S. (2018). Does globalisation worsen environmental quality in developed economies?. Environmental Modeling \& Assessment, 23(2), 141-156.

Stiftung, B. (2014). Globalization report 2014. Who benefits most from globalization?. Gütersloh: Bertelsmann Stiftung.

UN. (2015). United Nations Paris Agreement. Erişim adresi: https://unfccc.int/sites /default/files/english_paris_agreement.pdf.

Tatoğlu, F. Y. (2012). Illeri panel veri analizi: Stata uygulamalt. İstanbul: Beta.

Yay, G. G. ve Aksoy, T. (2018). Globalization and the welfare state. Quality \& Quantity, 52(3), 1015-1040.

Weib, J., Sachs, A. ve Weinelt, H. (2018). 2018 globalization report: Who benefits most from globalization?. Gütersloh: Bertelsmann Stiftung. 


\section{SUMMARY}

\section{Introduction}

Although globalization which has been effective in the change of the world for the last twenty years is being discussed in academic and political environments, it connects the economies of countries to each other by influencing the significant variables such as international trade, capital flows, innovative opportunities, and cultural ties. Globalization positively affects the economic growth and development of countries, however, it has negative impacts on the environment. In the globalizing world, environmental pollution and carbon emission cause disruption in the ecology and changes in the global climate. For this reason, globalization is closely related to sustainable development. The aim of this study is to analyze the effect of political globalization on sustainable development in developing and developed countries.

\section{Method}

Model no (1) is used to estimate the effect of political globalization on sustainable development which is also the aim of this study:

$\mathrm{Sd}_{\mathrm{it}}=\beta_{1} \mathrm{Sd}_{\mathrm{it}-1}+\beta_{2} \mathrm{Global}_{\mathrm{it}}+\varepsilon_{\mathrm{it}}$

In equation (1), $\mathrm{Sd}_{\mathrm{it}}$ represents sustainable development, $\mathrm{Sd}_{\mathrm{it}-1}$ represents the sustainable development of $i$ country in $\mathrm{t}-1$ period and Global represents the political globalization levels of

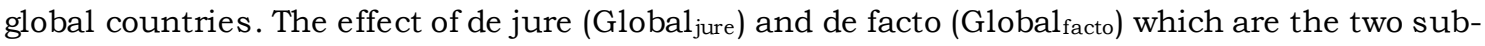
branches of political globalization variable on the de Sd of political globalization was analyzed. Global $_{j u r e}$ is the average of three different indicators which are the number of international institutions that a country is a part of, the number of international agreements that were signed between two or more countries and were approved by the supreme legislative organ of each country since 1945 and the number of explicit contracting parties of a country which has bilateral investment agreement. Global facto variable also consists of three indicators. The se are; the number of embassy in a country, the number of personnel that contributes to the duties of UnitedNations Security Council and the number of international-oriented non-governmental organizations (NGO) that a country is a member of. The data of the related variables that include the 1990-2015 period was obtained from the KOF Swiss Economic Institute (KOF). KOF data varies from 0 to 100 and the natural logarithm of this data was used in the analyses.

In their studies, Aidt (2010), Güney (2017) and Güney (2019) used the adjusted net savings (Ans) as an indication of sustainable development variable. Ans data was obtained from the WorldBank. Since Ans data showed negative and very high values, it was transformed into standard data with formula no (2) below. The data of the variable varies between 0 and 1 with this formula.

$$
\text { Standard Ans }=\frac{\text { Year Value-Minimum Value }}{\text { Maximum Value-Minimum Value }}
$$

In this study, System-GMM method which is a dynamic panel data model was preferred for the estimation of the equation no (1). In dynamic models, when the first difference of variables is taken, a part or all of the data of certain variables may be lost. Arellano and Bover (1995) who used orthogonal deviations method instead of taking the first variable prevented the data of variables to be partially or completely lost. On the other hand, in the dynamic models, the deferred value of the variable that is added as an independent variable to the model is also added as one of the explanatory variables to the same model. However, in this case, the deferred value of the independent variable becomes correlated with residuals. The obtained estimations may be 
inconsistent since these variables are correlated. It was suggested to use the instrumental variables instead of adding the deferred value of the independent variable to the model as an explanatory variable in order to eliminate the estimation inconsistency (Tatoğlu, 2012). It was proved that the estimation method suggested by Blundell and Bond (1998) was better than the methods that were suggested by Anderson and Hsiao (1981), Arellano and Bond (1991) and Arellano and Bover (1995) for overcoming the estimation problems that were stated above (Baltagi, 2005). For this reason, the estimation method that was suggested by Blundell and Bond (1998) was preferred in this study.

\section{Findings}

According to the estimations, political globalization has a positive effect on sustainable development in all of the countries that were included in the analyses. Thus, as the political globalization levels of countries increase, their sustainable development levels increase as well.

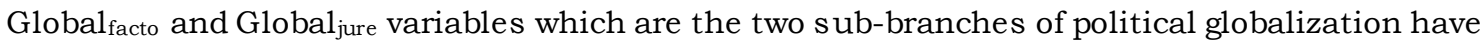

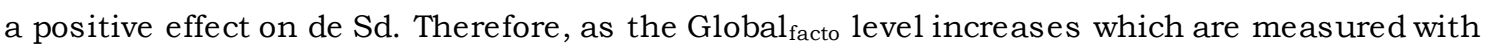
the variables of the number of personnel that contributes to the duties of United Nations Security Council and the number of international-oriented non-governmental organizations (NGO) that a country is a member of, the sustainable development level increases as well.

According to the System-GMM estimations that were obtained for developed countries, political globalization has a positive and statistically significant effect on sustainable development. Similar to the estimations that were obtained for all of the countries, Global facto $_{\text {and }}$ Global $_{\text {jure variables }}$ which are the two sub-branches of political globalization positively affect sustainable development. Global which is the political globalization variable has a positive and statistically significant effect on sustainable development. In addition to this, the effect of Global on Sd is much lower in developing countries than in developed countries. The effect of $\mathrm{Global}_{\text {facto }}$ and

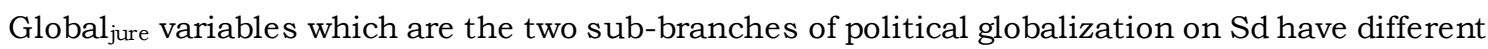
effects in developing countries.

\section{Conclusions}

The aim of this study is to analyze the effect of political globalization on sustainable development in 36 developed and 84 developing countries. Estimations indicated that political globalization positively affected the sustainable development level which was measured with adjusted net savings. This positive effect is higher in developed countries than the developing countries. Political globalization consists of two sub-variables as Global facto $_{\text {and }}$ Global $_{\text {jure }}$. The results of the analyses indicate that the Global jure which is the second sub-branch of political globalization increases the sustainable development level in developing and developed countries. On the other hand, Global facto has a negative effect on sustainable development in developing countries . 